Dickinson, David L. (2009) "The Effects of Beliefs versus Risk Attitude on Bargaining

Outcomes." Theory and Decision, 66(1): 69-101. Published by Springer Verlag. The

original publication is available at www.springerlink.com (ISSN: 0040-5833) (JAN 2009)

\title{
The Effects of Beliefs versus Risk Attitude on Bargaining Outcomes*
}

\author{
David L. Dickinson \\ Dept. of Economics \\ Appalachian State University
}

\begin{abstract}
In bargaining environments with uncertain disagreement or "impasse" outcomes (e.g., litigation or labor strike outcomes), there is an identification problem that confounds data interpretation. Specifically, the minimally acceptable settlement value from a risk-averse (risk-loving) but unbiased-belief bargainer is empirically indistinguishable from what one could get with risk-neutrality and pessimistically (optimistically) biased beliefs. This paper reports results from a controlled bargaining experiment where data on both risk attitude and beliefs under uncertainty are generated in order to assess their relative importance in bargaining experiment outcomes. The average lab subject is risk-averse, yet optimistic with respect to uncertainty, which is consistent with existing studies that examine each in isolation. I also find that the effects of optimism dominate those of risk-aversion. Optimistic bargainers are significantly more likely to dispute and have aggressive final bargaining positions. Dispute rates are not statistically affected by risk attitude, but there is some evidence that risk aversion leads to a weakened bargaining position. Though additional research is needed to understand the limits of extending these results, a key implication follows. In uncertainty environments where optimism dominates, increased settlement rates are more likely achieved by minimizing impasse uncertainty (to limit the potential for optimism) rather than maximizing uncertainty (to weaken the reservation point of risk-averse bargainers), as has been argued in the dispute resolution literature.
\end{abstract}

Keywords: risk preference, optimism, bargaining, experiments, dispute resolution JEL Codes: C91, D81, D84, J52

\section{running title: Optimism versus risk aversion}

*The author acknowledges funding for the bargaining application under National Science Foundation (grant \#0133231). This research was partially funded by the University Research Council at Appalachian State University. The author thanks an anonymous reviewer for many helpful comments. Valuable comments were also given by Doug Davis, Peter Wakker, Nat Wilcox, seminar participants at the University of Calgary, GATE (Lyon), and participants at the Economics Science Association meetings. 


\section{Introduction}

Theoretical research on bargaining has produced a well-known result that risk aversion will harm an individual's bargaining position, ceteris paribus. This result has been shown in a variety of game-theoretic models, including the highly influential models in Nash (1950) and Rubinstein (1982). ${ }^{1}$ Analysis of bargainer decision-making under uncertainty, such as in Farber and Katz (1979), produces a similar result in the sense that risk aversion in an expected utility framework lowers a bargainer's threat point (or certainty equivalent for the lottery). Laboratory data generally confirms the theoretical prediction that risk aversion harms bargaining outcomes, although estimated risk aversion effects are sometimes weak or dominated by other features of the bargaining situation, such as focal points or explicit disagreement costs (see Murnighan et al., 1988, Farber et al., 1990).

A separate strand of literature examines the effects of biased beliefs on bargaining outcomes under uncertainty. Though there exists evidence of pessimism in some environments (e.g., Hoelzl and Rustichini, 2005; Clark and Friesen, 2005), a good deal of research in psychology and economics has documented decision-maker overconfidence or belief-optimism in a variety of settings. ${ }^{2}$ Babcock and Loewenstein (1997) argue that many results from laboratory and field evidence on bargaining impasse (i.e., disagreement) are consistent with the notion that bargainers are overconfident or possess a self-serving bias in negotiations. Though such optimism may take more than one form-optimism about relative bargaining skills versus optimism about the likely

\footnotetext{
${ }^{1}$ This result does not hold only in the event that agreement outcomes are lotteries, as shown in Roth and Rothblum (1982).

${ }^{2}$ In general, both optimism and pessimism should be a concern. Context or framing is likely a determining factor-overestimating the odds of an uncertain but rare event, for example, may be considered pessimistic (acquiring food-borne illness) or optimistic (winning the lottery).
} 
decision rendered by a judge or arbitrator - this paper is specifically concerned with the optimistic belief that bargainers have over the uncertain outcome from impasse. Litigants, for example, are likely to have uncertainty about the final payoffs of going to trial versus settling out-of-court. There is also uncertainty surrounding disputed outcomes when they are settled through arbitration, which is increasingly used as a replacement for litigation for many civil disputes. If a labor union chooses to strike (i.e., dispute) rather than agree to management's contract offer, then the ultimate payoff outcome is typically not known with certainty by either management or the union. In general, one could consider that these environments all involve uncertainty or “ambiguous" lotteries (see Ellsberg, 1961), where probabilities over outcomes are unknown due to missing information.

It has been shown in an expected utility framework that the bargainers' contract zone - the region of outcomes mutually preferred to dispute - may theoretically disappear if bargainers are optimistic about the likely outcome from the impasse lottery (see framework in Farber and Katz, 1979). Both field and laboratory evidence indicate higher dispute rates when optimism is present (e.g., Neale and Bazerman, 1985; Farber et al., 1990; Babcock et al., 1995; Babcock and Loewenstein, 1997; Farmer et al, 2004; Dickinson, 2006). However, risk attitudes are not measured in these studies, and therefore represent a confound in the data interpretation. ${ }^{3}$

The theoretical effects of belief optimism work opposite the effects of risk aversion in terms of a bargainer's threat point or reservation value - the negotiated outcome that provides the same utility as playing the impasse lottery (i.e., the certainty

\footnotetext{
${ }^{3}$ Neale and Bazerman (1985) use a framing manipulation (gains v. losses) and assume risk attitude based on the frame of the negotiations.
} 
equivalent). ${ }^{4}$ This has important implications because the behavioral outcomes from a risk-averse individual who has optimistic beliefs can be observationally equivalent to those from a risk-neutral yet unbiased bargainer. In other words, the independent effects of risk attitude in the data cannot typically be identified unless one measures beliefs as well. A method is proposed in Wakker (2004) (utilized in Abdellaoui et al, 2005) for abstract individual decision-making environments, but is not appropriate for the present bargaining study. An example of this identification problem in bargaining experiment similar to the present one is found in Ashenfelter et al. (1992). Their data on final offers are said to be consistent with risk aversion, because bargainers demand less of the pie than predicted by risk neutrality when impasse outcomes are uncertain. However, observationally equivalent data could be generated by risk-neutral subjects who are pessimistic about the likely outcomes from impasse..$^{5}$

Existing bargaining research has examined both risk attitude and beliefs in isolation, while the decision theory literature has recently developed methods for decomposing risk preference and beliefs (Wakker, 2004). To this author's knowledge, there is no previous bargaining study eliciting subjects' home-grown preferences for risk and subject beliefs over uncertain impasse outcomes. Neale and Bazerman (1985) address both optimism and risk preferences in a mock negotiations experiment. However, they do not directly measure risk attitudes. Farber et al. (1990) examines the effects of risk aversion in a mock negotiations exercise in which bargainers are

\footnotetext{
${ }^{4}$ The theoretical framework in Farber and Katz (1979)_-presented in Section 2 - utilizes the concepts of certainty equivalents and contract zones to analyze the likelihood of dispute. For related work on the issues of dispute and outcome uncertainty, see Shavell (1982) and Priest and Klein (1982).

${ }^{5}$ Alternatively, if the Ashenfelter et al. (1992) subjects are, on average, risk-averse and optimistic, then results consistent with risk aversion may indicate that subject risk aversion dominates the subjects' optimism. The precise contribution of each factor is nonetheless unidentified.
} 
optimistic, but both risk aversion and optimism are induced in their research. The contribution of the present research is to use a two-stage experiment to first elicit subjects' risk attitude, and then conduct a second-stage bargaining experiment with uncertainty where subject beliefs are elicited. ${ }^{6}$ Because mock negotiations run the risk of introducing confounds into the data generation, I choose a more abstract bargaining experiment to limit potential confounds. ${ }^{7}$ Also, though risk attitude and/or beliefs may be sensitive to context or scale of payoffs, other controlled laboratory studies implement outcome uncertainty like the type examined in the present paper (e.g., Ashenfelter et al., 1992; Charness, 2000; Dickinson, 2004, 2006; Deck and Farmer, forthcoming). So, optimism (i.e., beliefs) may be an unidentified confound in some of the existing experimental bargaining research, and this paper hopes to contribute to our understanding of the likely impact of optimism relative to risk attitude in such data. Future research can help clarify the robustness of the present results in other environments.

The present data show that the average subject is risk-averse yet optimistic, consistent with previous research that has examined each separately. Optimism has a strong effect on increasing the likelihood of dispute, though it may improve one's outcome in a voluntarily negotiated settlement by making final bargaining positions more aggressive. Risk aversion does not have a statistically significant effect on dispute rates, but there is some evidence that it harms one's outcome in a negotiated settlement, as

\footnotetext{
${ }^{6}$ The reader will note that, though I assume an expected utility framework in generating testable hypotheses, the stage-one experiment allows one to control for risk attitude independent of the theoretical framework.

${ }^{7}$ Roth (1995) describes the concern with face-to-face context-laden experiments. While such experiments have clear value in bargaining research, there may be problems in interpreting their data. The issue is that these less-controlled face-to-face bargaining experiments introduce confounds into the data that are not easily quantifiable. In the end, this makes it more difficult to properly identify the desired treatment effects of an experiment. Of course, the trade-off is that more abstract experiments are less externally valid (i.e., less realistic). This explains why experiments in less controlled, but more realistic, environments are necessary to test the bounds or robustness of any theory.
} 
predicted by theory. Overall, the lab evidence indicates that the effects of beliefoptimism behaviorally dominate the effects of risk attitude in this setting. This is an important result for laboratory research on decision-making under uncertainty, because it highlights an important confound that may affect data interpretation when one is not careful to create well-known (i.e., pure risk) lotteries in the lab. If these results can be extended to naturally occurring bargaining situations where there is uncertainty surrounding the impasse outcome, these results have important implications on institutional design of dispute resolution procedures. If, as is likely the case, bargaining is an environment of uncertainty, then reduced dispute rates - a commonly used measure of bargaining or settlement procedure success - are more likely achieved by minimizing impasse uncertainty (to limit the potential for optimism) rather than maximizing uncertainty (to weaken the reservation point of risk-averse bargainers), as has been argued in the existing literature (see Stevens, 1966).

\section{Theoretical Framework}

Some specific hypotheses about the effects of risk attitude and beliefs are derived from the expected utility framework used in Farber and Katz (1979), on which the experimental design is roughly based. Specifically, consider a $B$ (buyer) and $S$ (seller) engaged in zero-sum bargaining over one dollar (or any fixed amount of money). Bargainer utility is defined as :

$$
U_{S}=\frac{1-e^{X C_{s}}}{1-e^{C_{s}}} \quad \text { and } \quad U_{B}=\frac{1-e^{Z C_{b}}}{1-e^{C_{b}}}
$$


where $x$ is the fraction of the pie player $S$ receives, and $z=1-x$ is the amount that player $B$ receives. With these parameterizations utility increases in the fraction of the pie received, with $U(0)=0$ and $U(1)=1$. Risk preferences are defined solely by $c_{i}$ for $i=b, s$, where $-c_{i}$ is the Arrow-Pratt measure of absolute risk aversion. As such, player $i$ is riskaverse (loving) when $c_{i}<(>) 0$. The buyer and seller have beliefs, $\mathrm{z}_{\mathrm{b}} \sim \mathrm{N}\left(\mathrm{z}_{\mathrm{bF}}, \sigma_{\mathrm{b}}{ }^{2}\right)$ and $x_{\mathrm{s}} \sim \mathrm{N}\left(x_{\mathrm{sF}}, \sigma_{\mathrm{s}}^{2}\right)$, respectively, of what the impasse outcome would be for themselves. Farber and Katz indicate that this framework is in contrast to one that distinguishes between risk and uncertainty, although it is clear that it allows for uncertainty belief bias rather than introducing pure risk. ${ }^{8}$

Farber and Katz (1979) derive the bargainers' certainty equivalents or reservation values, $X_{\mathrm{i}, \mathrm{R}}$ for $i=\mathrm{s}, \mathrm{b}$ : the lowest (highest) amount the seller (buyer) would be willing to accept (give) in a negotiated settlement. For the seller they show this to be $X_{\mathrm{s}, \mathrm{R}}=\chi_{\mathrm{sF}} \mathrm{F}(1 / 2) \sigma_{\mathrm{s}}{ }^{2} \mathrm{c}_{\mathrm{s}}$. Assuming that a bargainer is willing to accept any negotiated settlement providing a greater share of the pie then his reservation value, the seller is therefore willing to discount his lowest acceptable negotiated settlement if risk-averse, $c_{\mathrm{s}}<0$, and/or pessimistic, $x_{s}^{\text {pess }}<x_{s F}$. The opposite is true if the seller is risk-loving and/or optimistic. The buyer's reservation value is given by $Z_{b, \mathrm{R}}=Z_{\mathrm{bF}}+(1 / 2) \sigma_{\mathrm{b}}{ }^{2} \mathrm{c}_{\mathrm{b}}$. The buyer similarly discounts his reservation value if risk-averse and/or pessimistic. Alternatively, one could write the buyer's reservation value in terms of the maximum the buyer is willing to give the seller in a negotiated settlement, $X_{b, \mathrm{R}}=x_{\mathrm{bF}}-(1 / 2) \sigma^{2} \mathrm{c}_{\mathrm{b}}$, where

\footnotetext{
${ }^{8}$ Several non-expected utility frameworks assume decision-weight distortions in pure risk environments, such that risk attitude is simultaneously determined by both utility function curvature and probabilistic weighting (see Yaari, 1987, Tversky and Kahneman, 1992; Chateauneuf and Cohen, 1994; and Wakker, 1994 for examples). The optimism discussed in the present paper is not probabilistic optimism, and only in the present expected utility model can one interpret utility function curvature, $c_{i}$, as the sole indicator of risk attitude.
} 
$x_{\mathrm{bF}}=1-\mathrm{Z}_{\mathrm{bF}}$ is the buyer's expectation of what the impasse outcome would provide to the seller. Assuming a common $\sigma_{b}^{2}=\sigma_{s}^{2}=\sigma^{2}$ for simplicity (i.e., optimism is with respect to average outcomes, not outcome variance), Farber and Katz show that the contract zone, $\Delta$, of mutually beneficial bargaining outcomes is given by

$$
\Delta=\left(X_{b R}-X_{s R}\right)=\left(x_{b F}-x_{s F}\right)-\sigma^{2}\left[\frac{c_{b}+c_{s}}{2}\right]
$$

Equation (1) highlights the predicted effects of optimism and risk preferences on bargaining outcomes. A necessary condition for a positive contract zone, which I assume to be a measure of the likelihood of a settlement, is to either have average bargainer pessimism with respect to uncertain outcomes $\left(x_{b F}-X_{S F}>0\right)$ or average bargainer risk aversion $\left(c_{b}+c_{s}<0\right)$. Sufficient conditions also include the cases where risk-aversion dominates optimism, or where pessimism dominates any risk-loving preferences. Similarly, necessary conditions for no contract zone are optimism and/or risk-loving behavior. A more complicated noncooperative bargaining framework could be utilized, but it is noted in the introduction that these stylized results are common across numerous frameworks in the literature.

It should also be noted that this framework generates comparative static predictions on dispute rates and bargainer reservation values. Specifically, optimism increases reservation values, which I assume will lead to more aggressive final bargaining positions. Risk aversion not only moderates reservation values, but the extent to which it does is an increasing function of the uncertainty: $\frac{\partial X_{s R}}{\partial c_{s}}=(1 / 2) \sigma^{2}>0$, and similarly for the buyer. It is this result that leads to the familiar prediction that risk aversion harms one's bargaining position, ceteris paribus. Assuming that the contract 
zone is a predictor of dispute rates, belief-optimism is predicted to increase dispute rates, but an increase in a bargainer's level of risk aversion is predicted to decrease dispute rates to an extent that depends on the perceived impasse uncertainty, $\sigma^{2} .9$

\section{The Experiment}

Subjects participate in a two-stage experiment. In the first stage, subjects complete the lottery-choice experiment described in Holt and Laury (2002). Subjects face ten pairs of lotteries, and for each pair must state a preference for the safe or the risky lottery option. The total number of safe versus risky options chosen is used to generate a risk attitude variable, which is independent of any potential probability weighting. In other words, risk preference is captured in the first stage experiment, and will serve to remove the risk attitude confound from evaluating uncertainty beliefs in the stage-two experiment. Payoff amounts in the Holt and Laury low-payoff experiment are multiplied by two, which meant that the "safe" options had high/low payoffs of $\$ 4.00 / \$ 3.20$, while the "risky" options all had high/low payoffs of $\$ 7.70 / \$ .20$. Each of the ten pairs of lottery choices asks for the subject's preference of playing the Option A lottery (the safe gamble) or the Option B lottery (the risky gamble). The ten paired Option A/Option B choices differ by systematically varying the odds of winning the high (low) payoff amount from odds of $1 / 10(9 / 10)$ to $10 / 10(0 / 10)$. Subjects must state an option preference (or indifference) for each of the ten paired options, but only one will be

\footnotetext{
${ }^{9}$ There is some debate in the literature over the link between dispute rates and the size of the contract zone. Some argue that larger contract zones imply lower dispute rates (e.g., Crawford, 1982; Farber and Bazerman, 1987), but an alternative view is that larger contract zones imply more over which to dispute, thereby increasing dispute rates (e.g., Tracy, 1986; Crampton, 1992). The weight of the laboratory evidence is that optimism or decreased outcome uncertainty leads to higher dispute rates (e.g., Ashenfelter et al, 1992; Dickinson, 2006), and so we assume that smaller contract zones imply more likely dispute in the present paper.
} 
randomly selected for payoff at the end of the experiment. At the end of the experiment, a paired option is randomly selected for each subject individually, and the subject's preferred option choice is played out using a 10-sided die. Finalization of the first-stage lottery-choice experiment is deferred to the end of the experiment to limit wealth effects across experiment stages. Subjects are also made aware that their decisions from stage one do not affect earnings in stage two of the experiment, and vice-versa.

The second-stage experiment is the main bargaining experiment, and treatments that have uncertain impasse outcomes can be thought of as "arbitration" treatment. The experimental environment was designed to test a zero-sum bargaining framework similar to that of Farber and Katz (1979). Subjects were randomly assigned as buyer or seller (called Player "A" or "B", respectively, in the experiment) in a zero-sum bargaining experiment. It is common knowledge that subjects bargain with the same anonymous counterpart for the entire 15-round experiment. The players bargain over the variable X, and the buyer (seller) has a payoff table that shows cash payoffs per round are decreasing (increasing) in the level of X. Players are only aware of their own payoff Table, which showed payoffs ranging from $\$ 0$ to $\$ 2.50$, depending on the level of $X$. In order to limit the possibility of a focal point at half the pie, the buyer was given a suggested bargaining range for $\mathrm{X}$ of $[200,700]$ and a payoff tables based on the payoff function $\mathrm{P}_{\mathrm{b}}(\$)=1.00+(500-\mathrm{x})(.005)$. Similarly, the seller was suggested a range of $[300,800]$, and a payoff based on the function $\mathrm{P}_{\mathrm{s}}(\$)=1.00+(\mathrm{x}-500)(.005)$. So, the "pie" is actually $\$ 2.00$ 
per round and would be split at $X=500$, though this was not the center of either Player's suggested bargaining range. ${ }^{10}$

This use of asymmetric bargaining ranges is meant to simulate incomplete information concerning the counterpart's bargaining range - this improves the external validity of the environment. Though there may be concern that this design feature creates asymmetric information that may be confused with the effects of asymmetric beliefs, it should be noted that the information structure remains constant across all rounds and all treatments. While asymmetric information may then contribute to higher overall dispute rates, which are accounted for in the data estimation procedure as a pair-specific effects, it should not be a cause of differences across experimental treatments. ${ }^{11}$

Players participated in three distinct experimental treatments of 5 rounds each, which was unknown to the subjects, a priori. Each bargaining round is two minutes in length. If subjects reach the end of the round without having mutually agreed on a value of X, they are prompted to submit their "final offers", $\mathrm{x}_{\mathrm{b}}$ and $\mathrm{x}_{\mathrm{s}}$, for X. If final offers converge or criss-cross (i.e., $\mathrm{x}_{\mathrm{b}} \geq \mathrm{x}_{\mathrm{s}}$ ) then the value of $\mathrm{X}$ for the round is the average of the final offers - a last-minute settlement. If final offers fail to converge-what I will refer to as disagreement or dispute — then the dispute settlement process differs by treatment. In the NA (no arbitration) treatment, subjects both earn a zero payoff in the

\footnotetext{
${ }^{10}$ Player payoffs were not truncated at zero in the experimental application either. For example, if the buyer agreed to a seller proposal of $X=800$, then the buyer's earnings for the round would be negative, though negative earnings occur in less than $2 \%$ of the data.

${ }^{11}$ Some additional experiments were conducted that utilized the more structured ultimatum game (Guth et al., 1982), which is well-known in the experimental economics literature. Because the bargaining range is necessarily identical for both bargainers in the ultimatum game (i.e., players bargain for anywhere from all to none of a pie of known size), it is of interest that beliefs in a modified ultimatum game-one that utilized a random decision procedure at impasse - were unbiased. This may indicate that a portion of the optimism in the present unstructured bargaining experiments results from the asymmetric suggested bargaining ranges. At best, this would only partially explain optimism, because the results in Section 4 show that optimism increases in the higher variance CA treatment discussed in this Section, even though suggested bargaining ranges remain unchanged. These ultimatum results are available on request.
} 
event of dispute. In the other two treatments, a computerized random number generator determines the value of $\mathrm{X}$ for the round. The random $\mathrm{X}$ selection process is used to simulate the uncertainty surrounding the payoff outcome is dispute occurs, which may simulate the uncertainty of arbitration, litigation, continued dispute, termination of the bargaining relationship, etc. I refer to these two treatments as CA treatments (CA for Conventional Arbitration), and it is clear that the "cost" of these dispute settlement procedures is an uncertainty cost as opposed to the certain monetary cost of the NA treatment (see Stevens, 1966, for a useful discussion of this important distinction).

The two CA treatments differ with respect to the variance of the underlying normal distribution used to generate the settlement $\mathrm{X}$-values in the event of disagreement. In $\mathrm{CA}(30)$, the impasse outcome distribution has mean of $\mathrm{x}=500$ and standard deviation equal to 30 . The other treatment, $\mathrm{CA}(120)$ has the same mean but standard deviation of 120. So, the settlement outcome is much more uncertain in $\mathrm{CA}(120)$ than in $\mathrm{CA}(30)$, but in NA there is certainty that the entire pie is destroyed at impasse. In both CA treatments, the instructions include a table showing 100 draws from the exact CA distribution that would be used in the event of impasse to determine payoffs. This approach is used in Ashenfelter et al, (1992) as an information provision procedure that most likely mirrors the way in which bargainers gather information in the field (e.g., from seeing a history of previous arbitration decisions or court rulings). Importantly, this procedure also creates uncertainty and leaves ample room for subjects to form divergent beliefs about the likely outcomes from impasse (as noted in Dickinson, 2004). Subject always participate in the NA treatment from rounds 6-10, but whether $\mathrm{CA}(30)$ or $\mathrm{CA}(120)$ occur in the initial rounds 1-5 varies across subject groups. All subject pairs 
play all five rounds of each treatment consecutively prior to new instructions appearing on the screen to inform them of the treatment changes.

Beliefs are elicited prior to each round of bargaining in both CA treatments. Subjects are prompted on-screen to input their belief or expectation about the average outcome they feel they would get if the dispute settlement procedure were used. It is made clear that their response does not imply that they will have to use the dispute settlement procedure; voluntary settlement is always allowed at any point during the bargaining round or at the final offer stage if $x_{b} \geq x_{s}$. Subjects are given a small financial incentive to provide unbiased responses. One round is randomly selected at the end of the experiment, and a subject belief response in the selected round is rewarded with a $\$ 2$ payoff for accuracy - within 10 units of $\mathrm{x}$ above or below the true average of the dispute settlement distribution (i.e., a belief response in the interval [490,510]). The use of a randomly selected belief at the end of the experiment is also meant to minimize any potential wealth effect of the belief elicitation procedure on bargaining outcomes.

As designed, stage 1 and stage 2 of the experiment elicit risk attitude and beliefs in two distinct environments. Wakker (2004) develops a decomposition rule to elicit utility, decision weights, and beliefs in a way that is operationalized in a single experiment environment (Abdellaoui et al., 2005). However, their approach remains abstract and not amenable to a bargaining experiment. If we only conduct the stage-two bargaining experiment, it is unclear how one would separate risk attitude and uncertainty beliefs. We therefore estimate an independent measure of risk attitude for each subject prior to the uncertainty bargaining experiment.

\section{Results}


Sixty-three pairs of bargainers participated in the 15-round experiment described above. The experiment was finished within an hour, and the average subject payoff was $\$ 13.50$. Figures 1-3 plot out the cumulative distribution functions (CDFs) of subject risk preferences and beliefs. In Figure 1, the CDFs of risky choices, which proxy for subject risk attitude, are plotted against the CDF that would result from risk neutral subject choice (i.e., the risk-neutral subject would choose exactly six "risky" (and four "safe") choices in the Holt and Laury (2002) lottery choice experiment). One can test for differences in the buyer versus seller CDF using the Smirnov test for two-sample differences, which assumes that the distributions are independent. One fails to reject the null hypothesis of no difference in the buyer and seller CDFs ( $p>10$ for the two-sided test), but one rejects the null hypothesis that each of these CDFs is equal to the riskneutral benchmark $\operatorname{CDF}(\mathrm{p}=.10$ in each case for the one-sided test against the alternative hypothesis that the risk neutral CDF lies below the buyer or seller CDF). However, the median buyer and seller are both risk-neutral. Though we do find evidence of risk aversion, on average, the sample subjects are not highly risk-averse. ${ }^{12}$

Figures 2 and 3 show the belief-CDFs for buyers and sellers in the low-variance treatment, $\mathrm{CA}(30$ ), (Figure 2) versus the high variance treatment (Figure 3). The unit of observation in these figures is a subject's average belief, with respect to likely impasse outcome, over the five treatment rounds. The results are similar when using each individual belief as the unit of observation, but averaging over the five treatment rounds creates sixty-three independent blocks of observations. This allows appropriate use of

\footnotetext{
${ }^{12}$ The average subject risk aversion parameter, $r$, in Holt and Laury (2002) is in the $r=.3$ to $r=.5$ range (in their assumed expected utility framework). For comparison, average risk aversion parameters in this experiment are buyer $r=.23$ and seller $r=.12$. Our subjects are still estimated to be risk-averse, although somewhat less so than the subjects in Holt and Laury.
} 
the Smirnov full-sample test to examine the distributions of buyer and seller beliefs. In the low-variance treatment one fails to reject the hypothesis that buyers have unbiased beliefs ( $>$ >10) - this is tested against the unbiased benchmark that subjects always expect $\mathrm{x}=500$. However, using a binomial test for the number of instances where beliefs are optimistic versus unbiased or pessimistic, one rejects the null hypothesis in favor of the alternative hypothesis that buyers are optimistic $(\mathrm{p}=.05)$. For sellers, the Smirnov test rejects the null hypothesis of unbiased beliefs in the low-variance treatment in favor of the alternative hypothesis of seller optimism $(\mathrm{p}=.01)$, as does the binomial test $(\mathrm{p}=.10)$. One fails to reject the null hypothesis that the seller belief distribution is no different from the buyer distribution using the Smirnov test in the $\mathrm{CA}(30)$ treatment $(\mathrm{P}>.10)$. This indicates that optimism for the bargaining pair is not statistically significant in the low variance treatment.

In the high-variance treatment, $\mathrm{CA}(120)$, one rejects the null hypothesis of unbiased beliefs against the alternative of optimism for sellers but not for buyers using the Smirnov test $(\mathrm{p}>.10$ for buyers, $\mathrm{p}=.01$ for sellers). However, with the binomial test one finds support favoring the alternative hypothesis of optimism for both buyers and sellers ( $\mathrm{p}=.01$ in both cases). Using the Smirnov test, the seller belief distribution lies significantly beneath the buyer distribution $(\mathrm{p}=.01)$ in the $\mathrm{CA}(120)$ treatment - this indicates significant optimism for the bargaining pair in the high variance treatment.

In short, optimism is present in the data, and the nonparametric tests (as well as the pattern of the CDFs in Figures 2 and 3) indicate that subjects are more optimistic in the $\mathrm{CA}(120)$ treatment than in the $\mathrm{CA}(30)$. The summary data show that the average buyer belief of the likely impasse outcome in $\mathrm{CA}(30)$ is $\mathrm{x}=483$, but in $\mathrm{CA}(120)$ it is 
$x=467$. For the sellers, the average belief is an impasse outcome of $x=518$ in $\mathrm{CA}(30)$ and $\mathrm{x}=537$ in $\mathrm{CA}(120)$. As a whole, the data are supportive of the hypothesis that bargainers tend towards being optimistic towards outcome uncertainty, and their optimism is greater when the decision environment is more uncertain. ${ }^{13}$

\subsection{Dispute Rates}

Average dispute rates across all bargaining pairs for each treatment are NA (18\%), $\mathrm{CA}(30)(57.7 \%)$, and $\mathrm{CA}(120)(61 \%)$. If one calculates average dispute rates for a bargaining pair in each five-round treatment, then one can examine treatment effects as a matched pairs sample with $\mathrm{N}=63$ independent observations. Using the matched pairs (signed rank) test, one rejects the null hypothesis of equal average dispute rates in comparing the NA treatment to the $\mathrm{CA}(30)(\mathrm{p}<.01)$ and $\mathrm{CA}(120)(\mathrm{p}<.01)$ treatments in favor of the alternative hypothesis that disputes are significantly higher in the arbitration treatments. Though average dispute rates are higher in $\mathrm{CA}(120)$ than $\mathrm{CA}(30)$, one fails to reject to null hypothesis of equal average dispute rates when comparing CA(120) to $\mathrm{CA}(30)(\mathrm{p}=.21)$. I next turn to a more thorough econometric analysis in order to disentangle the effects of treatment, beliefs, and risk attitude from the data.

The data set includes a total of 945 observations when considering each round of bargaining by each subject-pair. Of course, since bargaining pairs are fixed for the entire 15-round experiment, the data across rounds are not likely to be independent of one another. In order to take this into account, all of the estimated models use a random effects specification to deal with pair-specific heterogeneity and correlation of error terms

\footnotetext{
${ }^{13} \mathrm{We}$ also find that there is no significant correlation between a subject's average belief and the number of safe choices in the stage-one experiment ( $\rho=.08$ for buyers and $\rho=-.10$ for sellers).
} 
across rounds by a given bargaining pair. In addition, history variables that describe the experience and dispute history of the pair in the experiment are included.

Table 1 shows estimates of a random-effects probit model. Dispute is coded as equal to one if the bargaining pair utilizes the dispute settlement procedure at the end of the round (NA or CA). Recall that if the round ends with no agreement but the subjects' final offers criss-cross (i.e., $\mathrm{x}_{\mathrm{b}} \geq \mathrm{x}_{\mathrm{s}}$ ), then this is coded as Dispute equal to zero- $\mathrm{a}$ lastchance settlement is achieved. Model \#1 is a simple treatment effects model-NA is the omitted reference treatment—with additional experience variables Round=1-15 and Dispute History=1-14. Round captures the potential effect of general experiment bargaining experience or learning, while Dispute History Ratio measures the distinct effect of bad history as proxied by the number of previous rounds of dispute, relative to the total, in which the bargaining pair has engaged.

The estimated marginal effects in Model \#1 indicate that there is a significant Round effect, but no significant effect of bad bargaining history as measured by Dispute History Ratio - this result is robust across all models in Table 1. In Model \#1 disputes are significantly more likely in either of the CA treatments compared to NA, which replicates results from previous experimental research (e.g., Ashenfelter et al., 1992; Bolton and Katok, 1998; Dickinson, 2004) and from field data results comparing dispute rates when arbitration is used to those when labor strikes are used - strikes are comparable to the high cost of dispute in the NA treatment (see Currie and McConnell, 1991). The marginal increase in dispute rates over the NA treatment is significantly higher in $\mathrm{CA}(120)$ than in $\mathrm{CA}(30)(\mathrm{p}=.05$ for the Wald test of the linear coefficient restriction on the two treatment variables). Unlike the results in Ashenfelter et al., 
(1992), I find evidence that disputes are more likely when outcome uncertainty is higher.

Significantly, this is opposite the conventional wisdom articulated in Stevens (1966) and modeled in Farber and Katz (1979), where arguments are made in favor of higher outcome uncertainty in order to promote more voluntary settlements - these arguments count on bargainer risk aversion, but they do not consider belief-optimism.

Model \#2 and \#3 results in Table 2 attempt to estimate any independent belief and/or risk attitude effects that are not controlled in the Model \#1 analysis. Specifically, Model \#2 adds a control for pairwise beliefs, Belief Difference, (seller minus buyer expectation of likely x-outcome at impasse) ${ }^{14}$, and Model \#3 then adds additional controls for bargainer risk attitude by utilizing the subject's number of safe choices, Risk aversion parameter, from the stage-one experiment as a proxy for risk aversion. Risk aversion is also interacted with the high variance $\mathrm{CA}(120)$ treatment - the latter is based on the comparative static predictions from the Farber and Katz (1979) framework. ${ }^{15}$ The results from Models \#2 and \#3 indicate that beliefs significantly alter the likelihood of dispute, but risk attitudes do not—perhaps due to relatively weak risk aversion of the subjects. A bargaining pair that is optimistic (Expectations Difference $>0$ ) significantly increases the likelihood of dispute, and this effect is robust to the addition of risk preference controls in Model \#3.

\footnotetext{
${ }^{14}$ This particular coding implies that beliefs are identical in the NA treatment, where beliefs were not elicited. Belief Difference is coded as equal to zero for all rounds of the NA treatment where the impasse outcome is known with certainty to be a zero payoff.

${ }^{15}$ None of the results differ if one instead uses the Holt and Laury (2002) risk aversion coefficients in place of the number of safe choices as the risk attitude control. It is noted previously that use of the number of safe choices controls for risk attitude independent of the chosen theoretical framework. The author thanks an anonymous reviewer for suggesting to use 'safe choices' as a framework-independent risk attitude variable. The empirical analysis is therefore more general than the theoretical framework used to highlight the intuitive hypotheses in Section 2.
} 
Though the magnitude of the marginal effects on $\mathrm{CA}(30)$ and $\mathrm{CA}(120)$ do not differ much across Models 1-3, together they show that dispute rate differences in $\mathrm{CA}(30)$ and $\mathrm{CA}(120)$ are captured by the risk attitude and beliefs variables. In other words, once controls are added for beliefs and risk preferences, there is no statistically significant difference in the likelihood of dispute in $\mathrm{CA}(30)$ versus $\mathrm{CA}(120)$ - the Wald test of this linear restriction is highlighted at the bottom of Table 1 . This is precisely what one would predict given that the two CA treatments present the bargainers with a mean preserving spread for the uncertain impasse outcome distributions. The inclusion of risk attitude and belief variables in Model \#3 imply that the pure CA treatment effects estimated are those for a risk-neutral and unbiased bargaining pair, which theoretically should not differ in dispute likelihood across any two CA treatments with identical average payoff outcomes.

\subsection{Final Bargaining Positions and Settlement Outcomes}

Though dispute rates are the most commonly used measure of a dispute settlement procedure's success, final bargaining positions are of significance as well. Final bargaining positions, $\mathrm{P}_{\mathrm{b}}$ and $\mathrm{P}_{\mathrm{s}}$, for the buyer and seller, respectively, are assumed to be functions of the certainty equivalents $X_{b, R}$ and $X_{s, R}$ from Section 2. Most logically, we theorize that $\frac{\partial P_{i}}{\partial X_{i, R}}>0$ for $i=\mathrm{b}, \mathrm{s}$. In other words, theory would predict that final bargaining positions are positively related to beliefs of likely x-outcomes at impasse, and bargaining positions are predicted to increase (decrease) in the risk aversion of the buyer (seller). Final bargaining positions at impasse-perhaps a measure of the aggressiveness

of the bargainer - can be a useful measure of how close the pair was to agreement. 
The results in Table 2 show random effects GLS estimates of a buyer and seller final bargaining position model — Lagrange multiplier tests favor use of random- or fixedeffects over a classical regression model. The dependent variable in this case, Final Bargaining Position, is coded as follows: when the round ends in dispute, Final Bargaining Position is equal to the subject's submitted final offer. When the round ends in voluntary settlement, Final Bargaining Position is equal to the settlement x-value. I therefore utilize the entire sample of treatment rounds (63 pairs times 15 rounds$\mathrm{N}=945$ ) in estimating the separate models for buyers and sellers. All independent variables are as described before with the exception of Beliefs in the NA treatment. The dispute rate probit model (Table 1) codes the pair's belief difference as zero in NA, but it is not appropriate to code individual expectations as zero in NA. While the pair is logically assumed to have identical beliefs of zero payoffs at impasse in NA, a zero payoff maps to a different $\mathrm{x}$-outcome for buyers and sellers. Beliefs are meant to elicit what $\mathrm{x}$-value (not what payoff level) the bargainer feels she is likely to get from the dispute resolution mechanism. As a result, because buyer payoffs are zero at $\mathrm{x}=700$, buyer beliefs are coded as equal to 700 in the NA treatment. For the same reason seller beliefs are coded as equal to 300 in NA.

The results from Table 2 confirm the belief hypothesis, but not the risk attitude hypothesis. The Beliefs variables indicate that final offers are significantly positively related to beliefs of the likely impasse outcome in the CA treatments. That is, optimism, which implies a higher (lower) belief for the seller (buyer) causes final bargaining positions to diverge. Though risk attitudes affect final bargaining positions in the direction one would predict, the effects are not statistically significant. Only in the buyer 
equation are Round and Dispute History Ratio significant, indicating buyers moderate final offers as experience is gained and when their cumulative dispute ratio is higher. ${ }^{16}$

Because beliefs and risk attitude are theorized to affect the boundaries of a bargaining contract zone, they are also predicted to affect settlement outcomes. Table 3 shows estimates of a model of voluntarily-negotiated settlements in the sub-sample of rounds ending in agreement $(\mathrm{N}=515)$. Given that voluntary settlement outcomes are a selected sample, I report results that correct for possible sample selection bias alongside the uncorrected random-effects estimates. ${ }^{17}$

As predicted by theory, settlements outcomes are positively related to the bargaining pair's average beliefs, though not significantly so in the non-sample-selection corrected model. Also, risk aversion significantly worsens the settlement outcome for the seller, which is consistent with theory. There is no significant difference in estimated settlement values across the two CA treatments, which is what one would predict once having controlled for beliefs and risk preferences. This alternative approach to estimating belief and risk attitude effects provides our only evidence that the risk attitudes of our subjects affect bargaining outcomes independent of belief-uncertainty.

In sum, the analysis indicates that optimism significantly increases the likelihood of dispute, it causes final bargaining positions to diverge, and it seems to influence settlement outcomes. The effects of risk attitude are not as conclusive or strong as the

\footnotetext{
${ }^{16}$ The bargaining position convergence result may be considered spurious due to the particular coding of final bargaining positions (i.e., agreement codes final bargaining position as equal to one another, and so optimism, which increases dispute rates, will generate some final offer divergence with this coding). However, utilizing only the selected sample of disputed outcomes $(\mathrm{N}=430)$ does not alter the result that optimism causes final bargaining position divergence. These results, available on request, include a correction for sample selection- the sample selection terms are significant in both the buyer and seller equations at the $\mathrm{p}=10$.

${ }^{17}$ The model test (F-test) is significant for the Heckit model, and the Lagrange multiplier test indicates a random- of fixed-effects model is more appropriate than a classical regression in the one-stage model.
} 
estimated belief-effects. Risk aversion, as proxied by the number of safe choices in the stage-one experiment, does not significantly influence dispute rates or bargaining positions, but there is some evidence that it harms one's settlement outcome. ${ }^{18}$

\section{Discussion/Conclusion}

Risk preferences and bargainer beliefs are two of the most commonly considered factors affecting bargainer behavior. Empirical studies have typically examined one or the other in evaluating bargaining outcomes. This is significant given that there is an identification problem inherent in evaluating outcomes from many bargaining environments with uncertain impasse outcomes. For example, given that the effects of belief-optimism are shown to counteract some of the predicted effects of risk aversion, the outcomes from risk-averse yet optimistic bargainers may be empirically indistinguishable from outcomes generated by risk-neutral and unbiased bargainers (or risk-loving yet pessimistic bargainers).

This paper presents results from an experiment designed to separate the independent contributions of naturally-occurring beliefs and risk attitude in bargaining outcomes. Subjects participate in a two-stage experiment. Stage one is the lottery choice experiment of Holt and Laury (2002), utilized to generate an estimate of subject attitudes towards pure risk. The second-stage experiment is a bargaining experiment that matches subjects in a zero-sum bargaining game for a series of rounds with different degrees of uncertainty surrounding the impasse or disagreement outcome. In the second-stage, probabilities over disagreement outcomes are not well-defined, as is likely the case in most naturally-occurring bargaining environments. In the CA treatments, a random

\footnotetext{
${ }^{18}$ If one replaces 'safe choices' with a risk-aversion parameter, which assumes an expected utility framework, then we find that the seller final bargaining position moderates for more risk-averse sellers, which is consistent with theoretical predictions outlined in Section 2 (results available on request).
} 
number generation process determines the outcome at impasse, and subject beliefs are elicited at the beginning of each CA round. Though subjects may be optimistic or pessimistic about other factors related to bargaining (e.g., relative bargaining skills), the beliefs I elicit are clearly aimed at measuring expectations of likely impasse outcomes.

The results are consistent with the prevailing wisdom that the average subject is risk-averse, yet forms optimistic beliefs under uncertainty. This, in and of itself, implies that an unbiased estimate of the effect of risk attitudes or optimism on bargaining outcomes will be difficult to acquire without measures of both to include in the data analysis. The analysis summarized in Tables 1-3 shows that optimism significantly increases the likelihood of dispute, significantly increases the divergence of final bargaining positions, and significantly alters voluntary settlements (in the direction favoring the more optimistic bargainer). The effects of risk aversion are not as ubiquitous, though when present they consistent with theory. Risk aversion does not significantly affect dispute rates, but voluntary settlement outcomes are biased in favor of the less risk-averse bargainer (i.e., the buyers) in these experiments.

The importance of these results is highlighted by the potential for drawing false inference from the data. Had these (unstructured) bargaining experiments not measured risk attitude or beliefs, the results might be casually interpreted as indicating that subjects are risk-loving, because disputes occur more frequently when impasse outcome uncertainty is highest. However, the experimental design allows us to identify that subjects are, in fact, risk-averse yet optimistic.

The result that optimism and risk aversion are simultaneously present is important to consider in designing a laboratory decision experiment and interpreting its data. That 
the effects of optimism are estimated to dominate those of risk aversion has significant implications in terms of optimal dispute settlement design. While outcome uncertainty has been considered a useful way to promote voluntary settlement (Stevens, 1966), outcome uncertainty is shown to foster the growth of optimism - optimism is worse in $\mathrm{CA}(30)$ than $\mathrm{CA}(120)$. The design of dispute settlement institutions aimed at promoting voluntary settlement might therefore be improved by limiting outcome uncertainty in order to limit the potential for optimism to influence bargaining outcomes. This is contrary to what has previously been argued in the literature, but it results from the fact that optimism may harm the likelihood of voluntary settlement more than the typical level of risk aversion helps it. A reduction in optimism would also increase convergence of final bargaining positions, which may help increase the quality of bargaining relationships even when disputes occur.

At this point, it is unclear whether the same relative effects of risk aversion and optimism would occur in higher stakes and/or naturally-occurring bargaining environments. Holt and Laury (2002) provide some evidence that risk aversion is larger for higher stakes gambles, which would counteract some of the optimism effects. Babcock et al. (1996) provide evidence that even experienced negotiators in naturally occurring setting (i.e., public school teach negotiations) possess a self-serving bias in how they view relevant information. So, it is unclear whether optimism would decline in importance simply by raising the stakes of the game, or by placing bargainers in a natural field context. ${ }^{19}$ These are clearly two useful extensions of this research that would help clarify the boundaries of the results.

\footnotetext{
${ }^{19}$ Hoelzl and Rustichini (2005) provide evidence indicating that optimism as to one's skills relative to others is more prevalent when tasks are perceived as simple and familiar. If their results can be applied to
} 
bargaining situations, then one would predict relatively more optimism for experienced versus novice bargainers. 

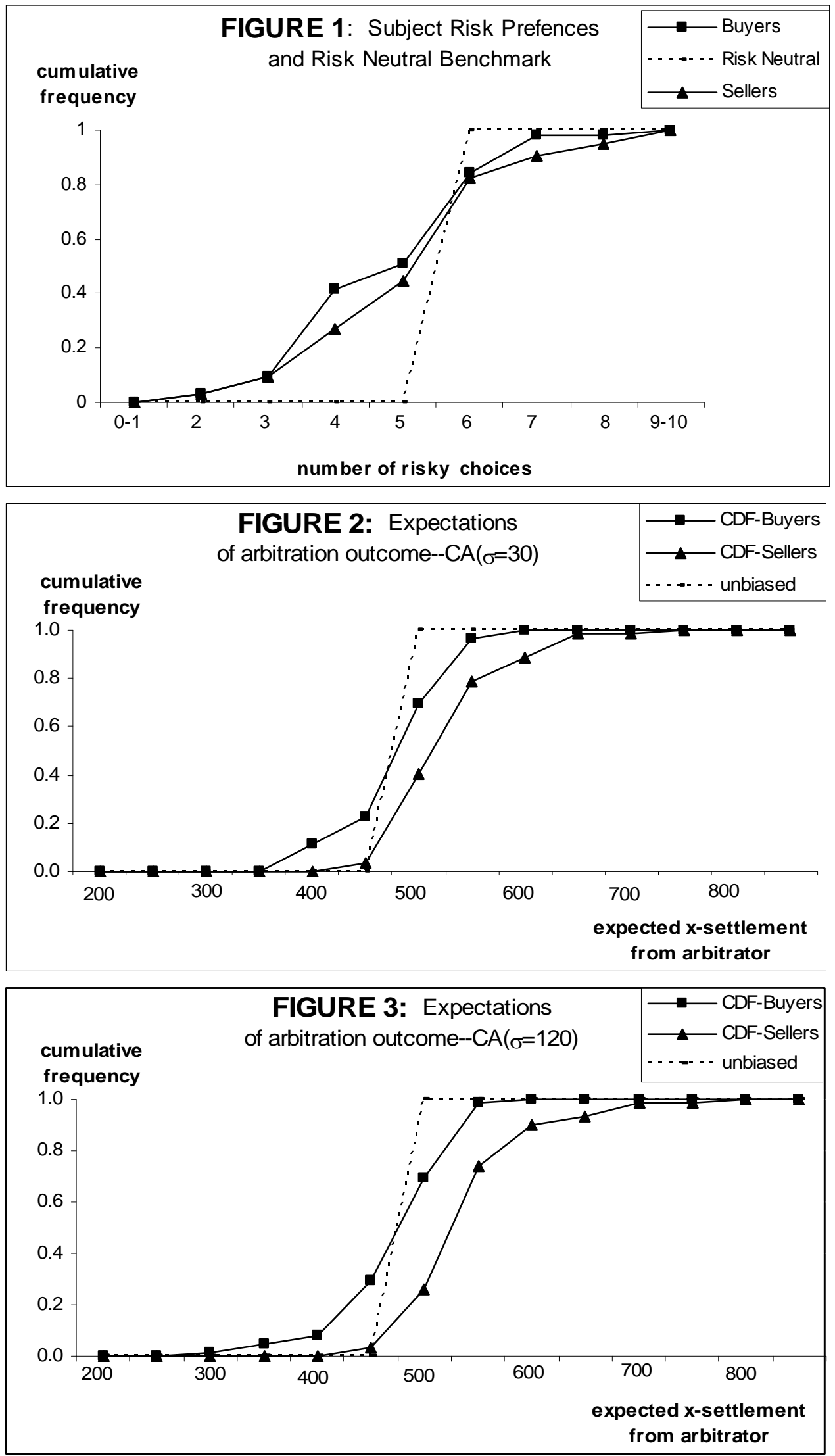


\begin{tabular}{|c|c|c|c|}
\hline \multicolumn{5}{|c|}{ Table 1 } \\
\multicolumn{5}{|c|}{ DISPUTE RATE MODELS } \\
& N=945 & \\
& MODEL \#1 & MODEL \#2 & MODEL \#3 \\
\hline Independent Variable & $\begin{array}{c}\text { Marginal effect } \\
\text { (st. error) }\end{array}$ & $\begin{array}{c}\text { Marginal effect } \\
\text { (st. error) }\end{array}$ & $\begin{array}{c}\text { Marginal effect } \\
\text { (st. error) }\end{array}$ \\
\hline Constant & $-.29(.05)^{* * *}$ & $-.29(.05)^{* * *}$ & $-.20(.18)$ \\
\hline CA(30) & $.42(.04)^{* * *}$ & $.39(.04)^{* * *}$ & $.40(.04)^{* * *}$ \\
\hline CA(120) & $.48(.04)^{* * *}$ & $.45(.04)^{* * *}$ & $.41(.15)^{* * *}$ \\
\hline Belief Difference & --- & $.0005(.0003)^{* *}$ & $.0005(.0003)^{* *}$ \\
\hline Buyer risk aversion & --- & --- & $-.03(.02)$ \\
\hline Seller risk aversion & --- & --- & $.01(.03)$ \\
\hline Buyer risk aversion*CA(120) & --- & --- & $.02(.02)$ \\
\hline Seller risk aversion*CA(120) & --- & --- & $-.01(.02)$ \\
\hline Round & $-.007(.003)^{* * *}$ & $-.008(.003)^{* * *}$ & $-.007(.003)^{* *}$ \\
\hline Dispute History Ratio & $-.02(.07)$ & $-.02(.07)$ & $-.02(.08)$ \\
\hline Wald test $\left(\boldsymbol{\beta}_{(\sigma=30)}=\boldsymbol{\beta}_{(\sigma=120)}\right)-\chi^{2}$ & $5.57^{* *}$ & $3.95^{* *}$ & .01 \\
\hline \% correctly predicted & $67 \%$ & $67 \%$ & $66 \%$ \\
\hline
\end{tabular}

$* * * * * *$ represent significance at the $.10, .05$, or .01 level, respectively, for the two-tailed test

\begin{tabular}{|c|c|c|}
\hline \multicolumn{3}{|c|}{$\begin{array}{c}\text { Table } 2 \\
\text { FINAL BARGAINING POSITION EQUATIONS } \\
\text { Dependent variable=Final Bargaining Position } \\
\text { (Random effects specification) } \\
N=945\end{array}$} \\
\hline & Buyer Equation & Seller Equation \\
\hline Independent Variable & Coeff. (st. error) & Coef. (st. error) \\
\hline Constant & $306.15(39.70)^{* * *}$ & $485.31(25.22)^{* * * *}$ \\
\hline CA(30) & $28.08(12.66)^{* *}$ & $-17.09(12.63)$ \\
\hline CA(120) & $40.22(22.01)^{*}$ & $-13.93(20.07)$ \\
\hline Belief & $.21(.05)^{* * *}$ & $.15(.05)^{* * *}$ \\
\hline Risk aversion & $1.88(3.88)$ & $-5.76(3.82)$ \\
\hline Risk aversion*CA(120) & $-4.05(3.75)$ & $3.57(3.46)$ \\
\hline Round & $1.40(.58)^{* *}$ & $.20(.57)$ \\
\hline Dispute History Ratio & $31.36(10.14)^{* * *}$ & $-6.37(10.30)$ \\
\hline
\end{tabular}

\footnotetext{
$*, * *, * * *$ represent significance at the $.10, .05$, or .01 level, respectively, for the two-tailed test
} 


\begin{tabular}{|c|c|c|}
\hline \multicolumn{3}{|c|}{$\begin{array}{c}\text { Table } 3 \\
\text { X-VALUE MODELS } \\
\text { Dependent variable=Agreement } \mathrm{X} \text {-Value } \\
\text { Subsample of voluntary agreements }(N=515)\end{array}$} \\
\hline & Two-Stage Heckit $^{\mathrm{a}}$ & Random effects model \\
\hline Independent Variable & $\begin{array}{l}\text { Coefficient } \\
\text { (st. error) }\end{array}$ & $\begin{array}{l}\text { Coefficient } \\
\text { (st. error) }\end{array}$ \\
\hline Constant & $434.91(65.53) * * *$ & $45246(65.23)^{* * *}$ \\
\hline CA(30) & $10.60(36.80)$ & $2.61(8.67)$ \\
\hline CA(120) & $54.87(62.54)$ & $39.65(44.64)$ \\
\hline Average Belief (of bargaining pair) & $.22(.11)^{* *}$ & $.16(.11)$ \\
\hline Buyer Risk Aversion & $-4.48(3.90)$ & $-2.54(4.19)$ \\
\hline Seller Risk Aversion & $-8.30(2.95)^{* * *}$ & $-8.20(3.90)^{* *}$ \\
\hline Buyer Risk aversion*CA(120) & $-5.17(6.81)$ & $-5.55(6.27)$ \\
\hline Seller Risk aversion*CA(120) & $-5.26(6.81)$ & $-2.75(6.32)$ \\
\hline Round & $1.29(1.27)$ & $1.12(1.00)$ \\
\hline Dispute History Ratio & $6.72(12.91)$ & $6.93(15.90)$ \\
\hline Lamba (sample selection term) & $-8.14(54.41)$ & --- \\
\hline
\end{tabular}

${ }^{a}$ The first-stage probit in this model is model \#3 from Table 1 (where the dependent variable is a dummy variable Settlement $=1$ when Dispute $=0$ and Settlement $=0$ when Dispute $=1$ ).

$*, * *, * * *$ represent significance at the $.10, .05$, or .01 level, respectively, for the two-tailed test 


\section{References}

Abdellaoui, Mohammed, Frank Vossmann, and Martin Weber. 2005. "Choice-based elicitation and decomposition of decision weights for gains and losses under uncertainty." Management Science, 51(9): 1384-99.

Ashenfelter, Orley, Janet Currie, Henry S. Farber, and Matthew Spiegel. 1992. "An experimental comparison of dispute rates in alternative arbitration systems." Econometrica, 60(6), pp. 1407-1433.

Babcock, Linda., and George. Loewenstein. 1997. "Explaining bargaining impasses: The role of self-serving biases." Journal of Economic Perspectives, 11(1): 10926.

Babcock, Linda., George Loewenstein, Samuel Issacharoff, and Colin Camerer. 1995. "Biased judgments of fairness in bargaining." American Economic Review 85(5): 1337-43.

Babcock, Linda., Xianghong Want, and George Loewenstein. 1996. "Choosing the wrong pond: Social comparisons that reflect a self-serving bias." Quarterly Journal of Economics, 111(Feb): 1-19.

Bolton, Gary E., and Elena Katok. 1998. "Reinterpreting arbitration's narcotic effect: An experimental study of learning in repeated bargaining." Games and Economic Behavior, 25: 1-33.

Charness, Gary. 2000. "Responsibility and effort in an experimental labor market." Journal of Economic Behavior and Organization, 42(3): 375-84.

Chateauneuf, Alain, and Michele Cohen. 1994. "Risk seeking with diminishing marginal utility in a non-expected utility model." Journal of Risk and Uncertainty, 9(1): 77-91.

Clark, Jeremy, and Lana Friesen. 2005. "Rational Expectations of Own Performance: An Experimental Study.” working paper, University of Canterbury.

Crampton, Peter. 1992. "Strategic delay in bargaining with two-sided uncertainty." Review of Economic Studies, 59: 205-225.

Crawford, Vincent. 1982. "A theory of disagreement in bargaining." Econometrica, 50(3): 607-637.

Currie, Janet., and S. McConnell. 1991. "Collective bargaining in the public sector: The effect of legal structure on dispute costs and wages." American Economic Review, 81: 693-718. 
Deck, Cary., and Amy Farmer. "Bargaining over an uncertain value: Arbitration mechanisms compared." forthcoming, Journal of Law, Economics, and Organization.

Dickinson, David L. 2004. "A comparison of conventional, final-offer, and "combined" arbitration for dispute resolution." Industrial and Labor Relations Review, 57(2): 288-301.

Dickinson, David L. 2006. "The chilling effect of optimism: The case of final-offer arbitration." Journal of Socio-Economics, 35: 17-30.

Ellsberg, Daniel. 1961. "Risk, ambiguity, and the savage axioms." Quarterly Journal of Economics, 75(4): 643-69.

Farber, Henry S., and Max H. Bazerman. 1987. "Why is there disagreement in bargaining?” American Economic Review, 77(2): 347-352.

Farber, Henry S., and Harry C. Katz. 1979. "Interest arbitration, outcomes and the incentive to bargain." Industrial and Labor Relations Review, 33(1): 55-63.

Farber, Henry S., Margaret A. Neale, and Max H. Bazerman. 1990. "The role of arbitration costs and risk aversion in dispute outcomes." Industrial Relations, 29(3): 361-84.

Farmer, Amy., Paul Pecorino, and Victor Stango. 2004. "The causes of bargaining failure: Evidence from Major League Baseball." Journal of Law and Economics, 47(2): 543-568.

Guth, W., Schmittberger, R., and B. Schwarz. 1982. "An experimental analysis of ultimatum bargaining." Journal of Economic Behavior and Organization, 3: 36788.

Hoelzl, Erik., and Aldo Rustichini. 2005. "Overconfident: Do you put your money on it?” The Economic Journal, 115 (April): 305-18.

Holt, Charles A., and Susan K. Laury. 2002. "Risk aversion and incentive effects." American Economic Review, 92(5): 1644-55.

Murnighan, J. Keith., Alvin E. Roth, and Francoise Schoumaker. 1988. "Risk aversion in bargaining: An experimental study." Journal of Risk and Uncertainty, 1: 10124.

Nash, John F. 1950. "The bargaining problem. Econometrica, 18: 155-162. 
Neale, Margaret. A., and Max H. Bazerman. 1985. "The effects of framing and negotiator overconfidence on bargaining behaviors and outcomes." Academy of Management Journal, 28(1): 34-49.

Priest, G. L., and B. Klein. 1984. "The selection of disputes for litigation.” Journal of Legal Studies, 13(1): 1-55.

Roth, Alvin E. 1995. "Bargaining Experiments." in John H. Kagel and Alvin Roth, eds., The Handbook of Experimental Economics. Princeton: Princeton University Press.

Roth, Alvin E., and Uriel G. Rothblum. 1982. "Risk aversion and Nash's solution for bargaining games with risky outcomes." Econometrica, 50(3): 639-48.

Rubinstein, Ariel. 1982. "Perfect equilibrium in a bargaining model." Econometrica, 50: 97-110.

Shavell, Steven. 1982. "Suit, settlement, and trial: A theoretical analysis under alternative methods for the allocation of legal costs." Journal of Legal Studies, 11(January): 55-81.

Stevens, Carl M. 1966. "Is compulsory arbitration compatible with bargaining?" Industrial Relations, 19(5): 38-52.

Tracy, Joseph. 1986. "An investigation into the determinants of U.S. strike activity." American Economic Review, 76: 423-436.

Tversky, Amos., and Daniel Kahneman. 1992. "Advances in prospect theory: Cumulative representation of uncertainty." Journal of Risk and Uncertainty, 5: 297-323.

Wakker, Peter P. 2004. "On the composition of risk preference and belief." Psychological Review, 111(1): 236-41.

Wakker, Peter P. 1994. "Separating marginal utility and probabilistic risk aversion." Theory and Decision, 36: 1-44.

Yaari, Menahem E. 1987. "The dual theory of choice under risk." Econometrica, 55(1): 95-115. 


\section{APPENDIX A: Text of experimental instructions (shown on screen in lab)}

Samples of screen-shots included in instructions can be viewed at http://www.appstate.edu/ dickinsondl/instructions.html

\section{General Instructions: Player A (layer B)}

This is an experiment in decision-making. Please read the following instructions carefully. The amount of money that you earn in this experiment will depend, in part, on your decisions as well as the decisions of the person with whom you will be randomly matched.

You have been randomly assigned as a Player A (Player B) in this experiment. You and a randomly chosen counterpart will be given a fixed amount of time in a decision-making round to mutually agree upon the size of a variable, $\mathrm{X}$.

[two-minute time limit announced by experimenter]

Your range of possible X values lies from 200 to 700 (300 to 800) in increments of one (this may not be the same range as that for your counterpart). The value of $\mathrm{X}$ at the end of the round will determine your cash earnings for that round. As a Player A (Player B), your cash earnings for any given round are largest (smallest) for smaller values of $\mathrm{X}$. Similarly, your cash earnings for any given round are smallest (largest) for larger values of X. You will be given a payoff sheet that translates the different values of X into earnings in cents. (Player B earns more for larger values of X). Please study this payoff sheet carefully so that you fully understand how your earnings will vary given the different possible values of $\mathrm{X}$.

\section{[payoff sheets handed out by experimenter]}

If you and your counterpart can mutually agree upon the size of $\mathrm{X}$ for that round, then you can look to your payoff sheet to determine how much you will receive for that round. In a few moments we will discuss what will happen should you and your counterpart not be able to come to an agreement by the end of the allotted time.

Your interaction with your counterpart will only be through the computer terminal. You will never know the identity of your counterpart and your counterpart will never know your identity. You are matched with the same counterpart for the entire experiment.

The next screen will show you the environment in which you will interact with your counterpart. If at any point during the instructions you have a question, please raise your hand so the experimenter can help you.

In your interactions with your counterpart, you will submit your proposal for the size of $\mathrm{X}$ on this screen

[sample screen picture]

To enter a proposal for X, click on the "New Offer" box, enter a proposal for X and then hit "Offer". Note: The sample screens are based on player A's point of view. 
At this point, Player B will see Player A's current proposal and may or may not accept it. Player B can similarly make proposals that Player A sees in the counterpart's box at the right of the screen. Suppose that Player B wishes to propose $X=600$ rather than accept Player A's current offer.

\section{[sample screen of offer]}

In this example, Player B's proposal is seen to be $X=600$. This is listed as his/her current offer. Player A may accept the current offer at any time by clicking the "Agree" button.

If you accept the current offer of your counterpart, the round would be over. You may, however, choose to not accept the current offer. You can update your current offer by increasing or decreasing it, and your counterpart can also update his/her offer. After updating an offer, it will be reflected in your offer box. Only current offers (offers at the top of the list) can be accepted. Even though offers can be updated at any time, it may be wise to give the other Player a few moments to either accept your offer or update his/her offer.

Suppose that you did not accept the proposed offer and you enter another offer.

[sample screen of a new offer]

At this point, your counterpart will see your current proposal for 349 [in this example] as well as all previous proposals for this round. However, only $\mathrm{X}=349$ will be listed as the current offer. As such, your counterpart may now choose to either accept your proposal or update his/her proposal. Let's suppose that your counterpart choose to accept your proposal at this point.

[sample screen of offer acceptance]

Your counterpart has accepted your offer, and so $X=349$ for that round. Once the round is over, either another round of similar interactions will occur, or instructions will follow to indicate the differences in the subsequent round(s). You will be asked to indicate when you are ready to continue with the experiment.

The computer will keep track of your cumulative experimental earnings and post them on your main computer screen. You will also have a timer on the screen to let you know how much time is left in a particular round. Please take a moment to locate these information items on your screen once bargaining begins.

The next several screens will inform you as to what will happen should you not come to an agreement within the time limit.

\section{Treatment Instructions: NA}

For the next several rounds, there will be a particular procedure used to deal with the possibility that you and your counterpart may not reach an agreement by the end of the round. Should you reach the end of the round without having mutually agreed upon a value of X, you will then be prompted for a final offer. If you and your counterpart's final offers come to agreement, then that is the value of $\mathrm{X}$ for the round (if they overlap, 
then $\mathrm{X}$ will be the average of the final offers for that round). If there is still no agreement, then you will both receive $\$ 0$ for that round. This does not affect any of your previous earnings, nor does it apply to future earnings (future rounds of the experiment). It is important for you to understand this rule. The screen below shows you what you would see if the round were to end in this scenario.

[sample screen of round ending without agreement]

This procedure of dealing with no agreement at the end of the round will continue until you are otherwise notified. When you have finished the last round of this procedure, you will be notified through the instruction boxes on your computer screen. If you have any questions before starting this set of rounds, please raise your hand now. Otherwise, click below to start.

\section{Treatment Instructions: CA}

For the next several rounds, there will be a particular procedure used to deal with the possibility that you and your counterpart may not reach an agreement by the end of the round. Should you reach the end of the round without having mutually agreed upon a value of X, you will then be prompted for a final offer. If you and your counterpart's final offers come to agreement, then that is the value of $X$ for the round (if they overlap, then $\mathrm{X}$ will be the average of the final offers for that round). If there is still no agreement, the computer will generate a value of $\mathrm{X}$ for you. Some values of $\mathrm{X}$ are more likely to be chosen than others, but there is a random element to the computer's choice. Whatever value of $X$ the computer randomly generates, that will be the value of $X$ used to determine both your and your counterpart's payoffs for that round. To give you some information about this random number generation procedure, the next screen will show you the last 100 values of $X$ generated by the exact same method that will be used in your case (should you not reach an agreement prior to the end of the round).

These are the last 100 values of $\mathrm{X}$ randomly generate by the computer (The order in which they are shown is irrelevant). This should be used to give you an idea of more likely and less likely values of X.

[sample 10x10 table of $100 \mathrm{X}$-values drawn from appropriate high or low variance distribution (X-values are rounded to nearest integer)]

Again, if you and your counterpart have not reached agreement by the end of the round, you will be prompted for a final offer. If final offers still do not agree, then the same random number generation procedure that generated these 100 values of $X$ will be used to determine your value of $\mathrm{X}$ for that round. If you have any questions before starting this set of rounds, please raise your hand. Otherwise, click below to start. 